\title{
Multimedia Teaching Platform Construction Based on Flash Interaction Technology for Gymnastics
}

\author{
https://doi.org/10.3991/ijet.v13i05.8441 \\ Changhui Xia \\ Hubei University of Arts and Science, Xiangyang, China \\ shangwei12 @yeah. net
}

\begin{abstract}
The rapid development of mobile multimedia technology provides broader space for improvement of distance teaching system. It is very difficult for the previous multimedia technology to meet people's requirements for informatization and intelligentization of multimedia teaching. The appearance of Flash technology offers the new thought for multimedia teaching. Flash not just supports image, voice and video, but also owns thorough object-oriented program design and can achieve interaction among multimedia of different types. In this paper, based on functional framework and distance question answering sub-system, multimedia teaching platform for Gymnastics based on Flash was constructed. Besides, the course Gymnastics was taken for example to carry out effect test, in the hope of offering data support for improvement and promotion of multimedia teaching platform and exploiting future potential development direction of network teaching.
\end{abstract}

Keywords-Flash interaction technology, multimedia teaching platform, Gymnastics course, distance teaching

\section{Introduction}

Mobile multimedia technology owns all functions of traditional multimedia and can excellently complete multimedia teaching task. It has been an emerging teaching mode in recent years. Mobile multimedia can increase classroom teaching capacity and make the distance between the teacher and students close so as to improve reaching efficiency and quality [1]. In such background, mobile multimedia technology becomes the basis of distance teaching system and plays an important role. Distance teaching system [2] is a new mode with individuation and intelligentization which is improved on the basis of traditional teaching mode. Through distance teaching system, learners can achieve independent study, and are more flexible in space and time. Hence, their learning efficiency will significantly improve. Common distance teaching system includes such sub-systems as on-line study and management, courseware making, and virtual classroom, and can achieve such functions as online study, course management, resource sharing and real-time interaction. At present, intelligent distance teaching system is mainly applied in excellent network course teaching, and the linkage between multimedia teaching, and relevant expert webpage and academic 
forums has been implemented preliminary. The thorough distance teaching system is being constructed gradually to make it applied in teaching more subjects and more levels [3].

However, current multimedia teaching generally has such problems as poor interactivity and the disconnection between teachers and students. It is required to seek more appropriate network multimedia technology. The development and improvement of Flash technology offer the new possibility for the improvement of distance teaching system. With powerful interaction function and multimedia display function, Flash technology has been successfully applied in numerous fields. The research and development of multimedia teaching system based on Flash technology will effectively solve a series of problems in distance teaching, then greatly relieve teaching cost and provide learners with highly individual and intelligent learning environment. Multimedia teaching system based on Flash technology developed in this paper will achieve doth-way interaction, synchronous courseware transmission and other functions, and can drive the development of distance teaching system, make it applied in more extensive teaching and fundamentally promote generalization of distance teaching.

\section{State of the art}

Compared with traditional teaching mode, distance teaching is characterized by convenience, strong interactivity and large resource capacity, so it has received extensive attention from domestic and overseas scholars. PE and medicine teaching have high requirements for vividness of course content and initiative of course learning, so people often take distance teaching system in PE and medicine teaching is the object of study. Based on business process analysis, Pan [4] conducted the design of multimedia teaching platform based on WEB. The platform includes three sub-system: teaching management, online teaching and independent study. Through the multimedia teaching platform, students can learn courses, participate in teaching activities online and achieve network interactivity with students and teachers. Hui [5] deeply analyzed the application of streaming media technology in distance teaching and considered that, streaming media technology have obvious advantages in file transfer and playing. The application of streaming media technology in teaching courseware provides rich expressive force for teaching courseware. Multimedia courseware has become an indispensable content in network teaching resource. Zhou [6] took higher vocational colleges for example to study the application of video conference system in distance teaching and proposed the specific application mode off video conference system according to the problems existing in higher vocational education. The scholar considered that, multimedia teaching system represented by video conference system has great significance for improving teaching quality of higher vocational colleges. Although multimedia technology represented by WEB technology and streaming media technology have gained a good effect on distance teaching, the problems of previous multimedia technology such as poor interactivity and poor learning experi- 
ence cannot be ignored. The problems of high teaching cost and slow information transmission in distance teaching become the main factors restricting its development.

Some scholars have noticed the problems of current distance teaching system and improved it through introducing advanced multimedia technology. Flash becomes one of reliable technologies of distance teaching system improvement by virtue of its high interactivity and fast transmission. Da [7] et al. designed distance teaching platform based on Flash technology for the poor interactivity of distance teaching system, developed the teaching video with question asking function by referring to classroom question asking mode and achieved the real-time interaction of teaching resource. The distance teaching platform obtained a good effect in practice. Guo [8] designed Flashbased multimedia interactive courseware and focused on the analysis of interactive courseware making, use and maintenance, in the hope of facilitating innovation and development of distance education in information technology background. Ubul [9] conducted preliminary design of Flash-based multimedia interaction teaching platform and put forward the making thought of multimedia interaction teaching platform on the basis of analyzing detailed features of Flash technology. The multimedia teaching platform includes three modules: knowledge explanation, practice simulation and example making. The teaching contents are rich and vivid, and can effectively motivate students' learning interest. It has gained good feedbacks in practice.

In general, previous Flash distance teaching system has such problems as poor interactivity, disconnection between teachers and students, non-smooth exchange between teachers and students [10], difficulty in live transmission of teacher's teaching plan, manpower and material resource consuming in teaching process recording and saving, high cost, and few matched resources for students' autonomous learning. To solve the above technical problems, Flash-based multimedia teaching platform in this paper will be the trend of distance teaching development and has great significance for improving system convenience and meeting students' individual needs. However, Flash-based multimedia teaching platform is still in the research and test stage, and it needs to be further improved according to teaching practice.

Flash-based multimedia teaching platform is designed in accordance with the development trend of distance teaching. Through introducing Flash technology, poor interactivity, slow transmission of teaching resources and high cross problems are solved. Flash-based multimedia teaching platform owns the following advantages. On the one hand, Flash-based teaching platform can achieve the function of both-way video interaction, greatly improves transmission speed of multimedia resource and work out supporting facility problem which restricts distance teaching development. On the other hand, for the needs of distance teaching, a distance question answering system is implanted in multimedia teaching platform in this paper, and can achieve synchronization of online answering and offline answering and then improve distance teaching quality. 


\section{Theory construction based on Flash interaction technology}

Flash is a kind of software with animation creation and application program development which is launched by Macromedia, and it is mainly used to create digital animation, interactive Web site, desktop application program and mobile phone application program. Flash technology is often applied in creation of application programs containing multiple types of multimedia resources. Flash types are rich, including simple animation, video content and PPT. meanwhile, it can construct Flash application program containing rich media through program combination.

\subsection{Features of Flash interaction technology}

Flash interaction technology has the following features:

1. Flash technology can provide rich video services, including video on demand, live network broadcast, video interaction and audio chatting, etc. The latest Flash Media Server 2 owns unique programmable streaming media environment and can achieve accurate control of media stream, customized interaction and user authentication. It further improves user experience.

2. Flash is easy to operate, with high compatibility. Flash can operate on existing Windows or Linux server, and fast achieve the connection with database and World Wide Web. Extension function of Flash can conduct XML-based media metadata management and local system resource visit, and offer more fluent media experience with users.

3. Flash is very secured. There is no exposed URL and media field position in Flash. External medial file position will be compressed into binary format in Flash. Users may customize media player through Flash to ensure file security in the database. Flash can verify user identity through access control, support encryption delivery of practical stream through SSL and furthest guarantee user security.

4. Flash owns good expansibility. The introduction of edge server makes user demand gain the response fast. Routing management offers the possibility for users to handle teaching platform connection. The operation of multi-process makes users able to operate medial application as an independent course.

\subsection{Shared object}

Under Flash technology, any data type supported by Flash can be stored in the shared object, including local storage and distance server storage. Through the shared object, different users can use the application program under the sane server. Flash mainly supports two shared objects: local and distance.

Local shared object is responsible for storing local data in the user's computer, and can be visited by other application programs at different time. The method to establish and access local shared object is as follows:

var myso=SharedObject.getLocal('myCookie')

myso.data.mydata='testpro'; 
so.data.msg='test_data';

Distance shared object implements the establishment of shared data for different online users through ActionScript program of Flash. Distance shared object is stored at the server, so the application scope is more extensive. The method to establish distance shared object is as follows:

var client_nc=new NetConnection();

client_nc.connect('rtmp://localhost/videochat/room1');

so.connect(client nc);

Data reading and writing of distance shared object are similar to local shared object. The statement is as follows:

so=SharedObject.getRemote('records',client_nc.url,true);

\subsection{Camera object}

Camera object can complete video capture, video transmission, video display and recording, etc. It is mainly used to implement the functions of video conference and video chatting. The codes to create Camera object are as follows:

MyCamera $=$ Camera.get();

MyCamera $=$ Camera.get(index);

Users can gain better transmission quality through setting the mode of Camera object. After completing the user of Camera object, it is also necessary to use NetStream.attachVideo(false) in order to make sure Camera object is closed.

\subsection{NetConnect object}

NetConnect object does not support http protocol, so Flash server cannot directly conduct data exchange with backstage program, which can only be implemented through calling client with call method. NetConnect object outputs and returns information according to the following procedure:

client_nc.onStatus=function(info) \{

trace('info.type:'+info.level+newline+' info.content:'+info.code);

switch(info.code) \{

case'NetConnection.Connect.Success':

trace('Connect success');

braek;

\}; ;

To keep procedure integrity, connection is conducted when procedure or connection is not used or quits. Generally, srcStream.close() is first used to stop data stream object and then connection.close() is used to close connection. 


\section{Construction flash-based multimedia teaching platform for Gymnastics}

\subsection{Functional framework design}

Multimedia teaching platform should be able to not just meet traditional teaching needs, but also highlight the advantages of multimedia teaching so as to adapt to teaching requirements of different courses. Functional framework design of Flashbased multimedia teaching platform is as Fig.1.

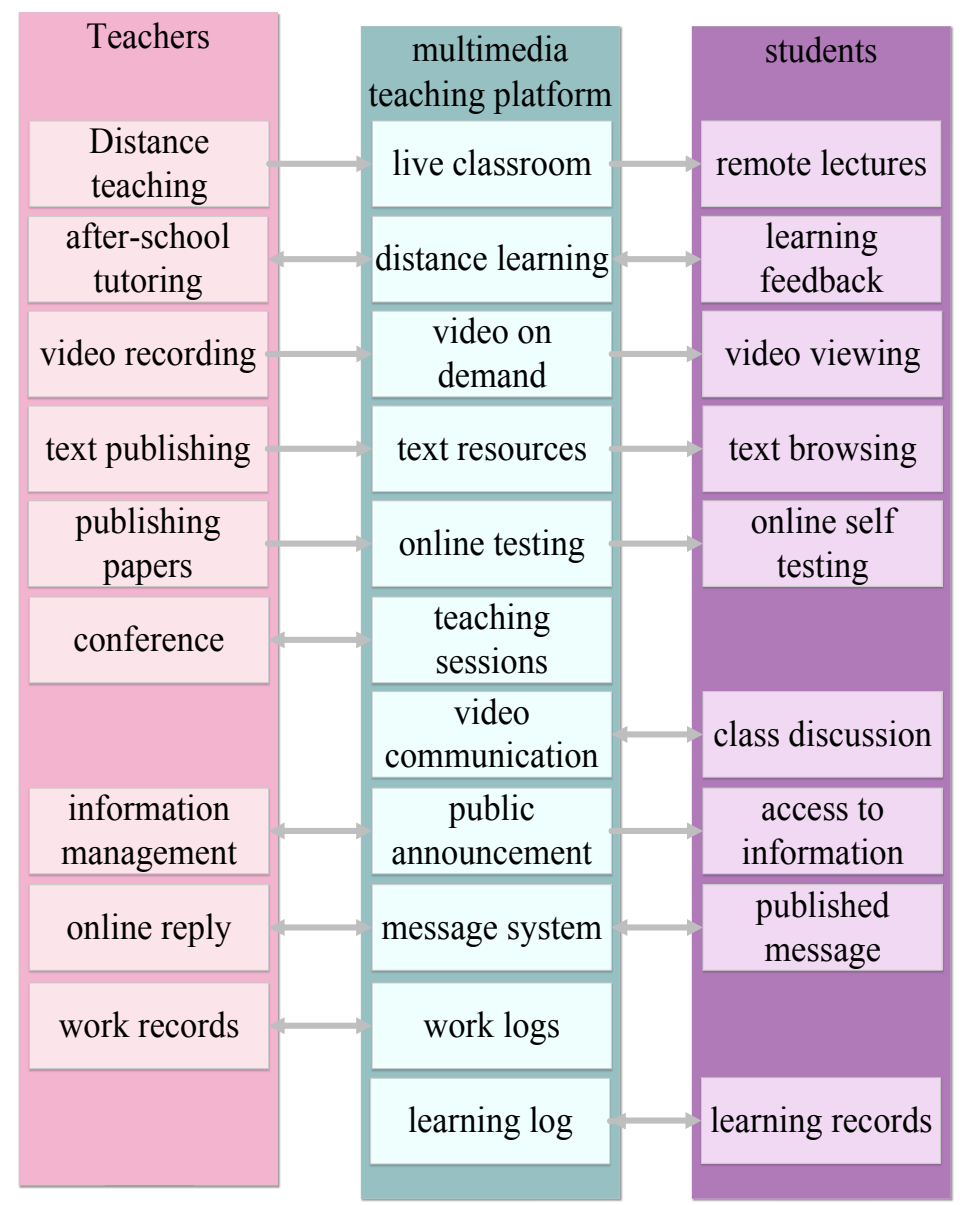

Fig. 1. Functional framework of Flash-based multimedia teaching platform

The multimedia teaching platform designed in this paper owns abundant functions: live-transmission classroom is a virtual classroom and can be used for teacher's distance teaching and student's distance listening. Fast communication of teaching re- 
sources can be implemented through video streaming service technology of Flash to meet the demand of multi-subject teaching and offer rich multimedia courseware for distance teaching. Distance question answering is used for extracurricular tutoring in teaching link. It answers students' questions in time through the connection of audio/video steam between students and teachers. The application of video on demand offers a convenient channel for students' independent study. Teachers can record and publish teaching video through this module. Students can selectively watch videos. Text resource summarizes course-related resources, including document and diagram files. Students can seek learning materials from it. Online testing is used for students' stage examination. It is an effective means for teachers to test teaching progress and teaching quality. The teacher publishes test questions in this module in advance. After students finish stage study, they may extract test questions at random from the test question bank to test learning effect. The system will summarize students' test results and then analyze the progress of the course. The design of teaching conference module can offer teleconference and teaching discussion place for teaching management personnel to effectively solve the problem that teachers and management personnel are too disperse and the teaching objective is vague. Video exchange module is a place for students' exchange and sharing. Students can display learning progress and learning problems through video and text modes so as to improve learning efficiency. In addition, announcement notice, message board system, job blog and earning log in multimedia teaching platform are designed for distance teaching features. It is mainly used for routine teaching arrangement and teaching management. The interface of multimedia teaching platform is shown in Fig.2:

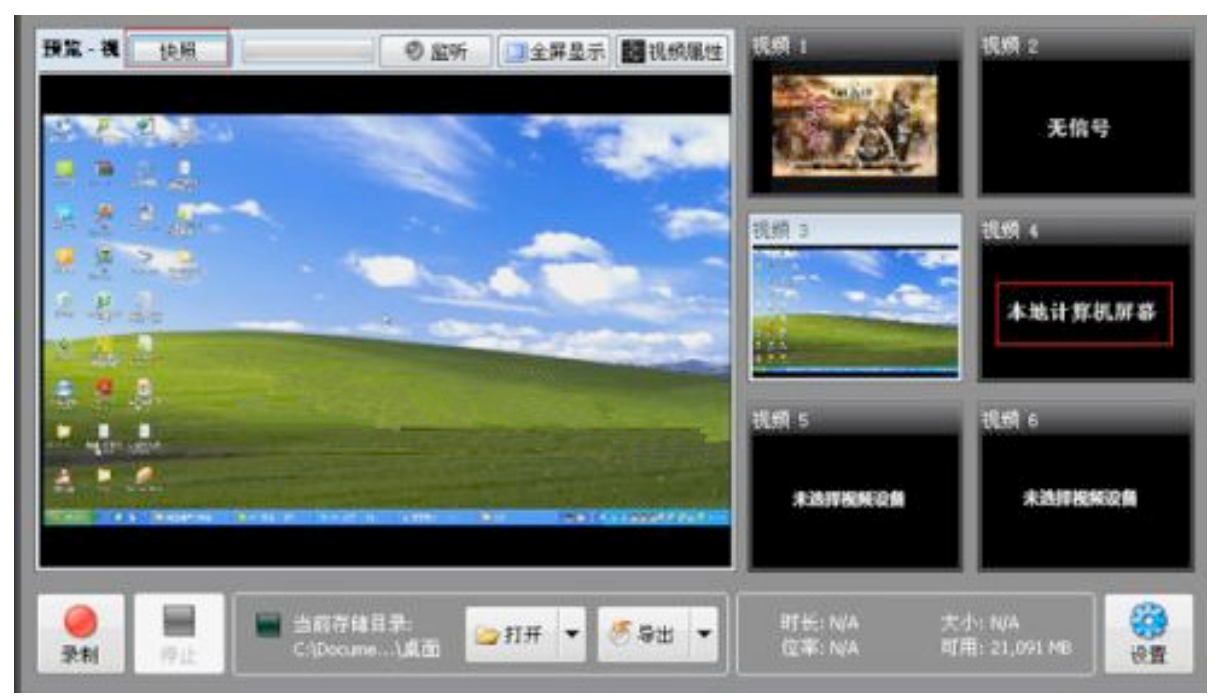

Fig. 2. Interface of multimedia teaching platform 


\subsection{Design of distance question answering sub-system}

Flash-based multimedia teaching platform highlights interaction characteristic of Flash technology, and thoroughly improves the problem of non-smooth communication between teachers and students in the previous distance teaching. Structure diagram of distance question answering sub-system is shown in Fig.3:

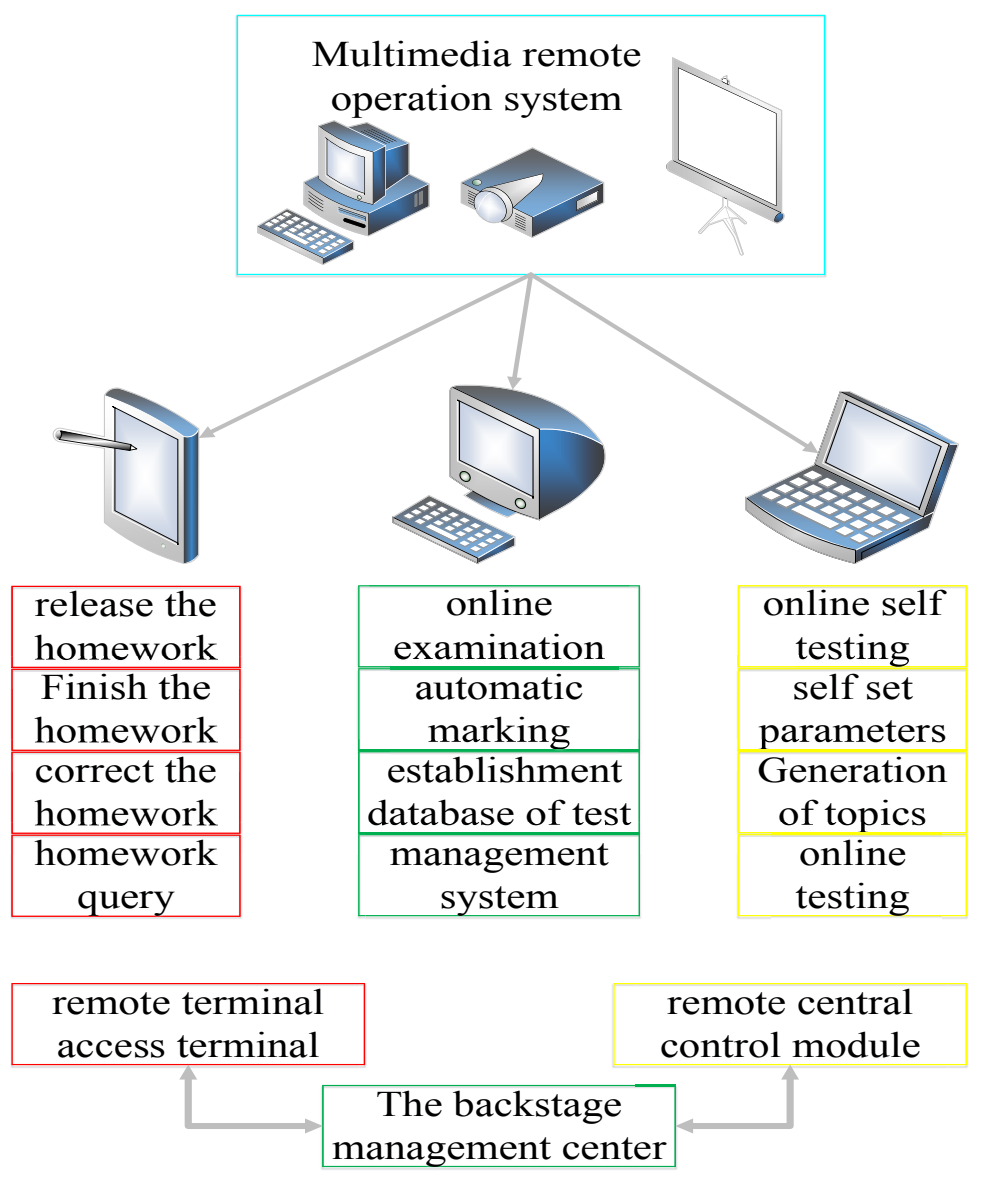

Fig. 3. Structure diagram of distance question answering sub-system

In Fig.3, the access terminal of remote terminal in distance question answering sub-system is used to access network to backstage management center of the system and implement user identify entry, authentication and course information selection. Distance center control module is responsible for wireless data communication with multiple backstage management centers. The system includes three subsystems: distance operation subsystem, distance examination subsystem and student self-test subsystem. The specific structure of distance backstage management center is shown in Fig.4: 


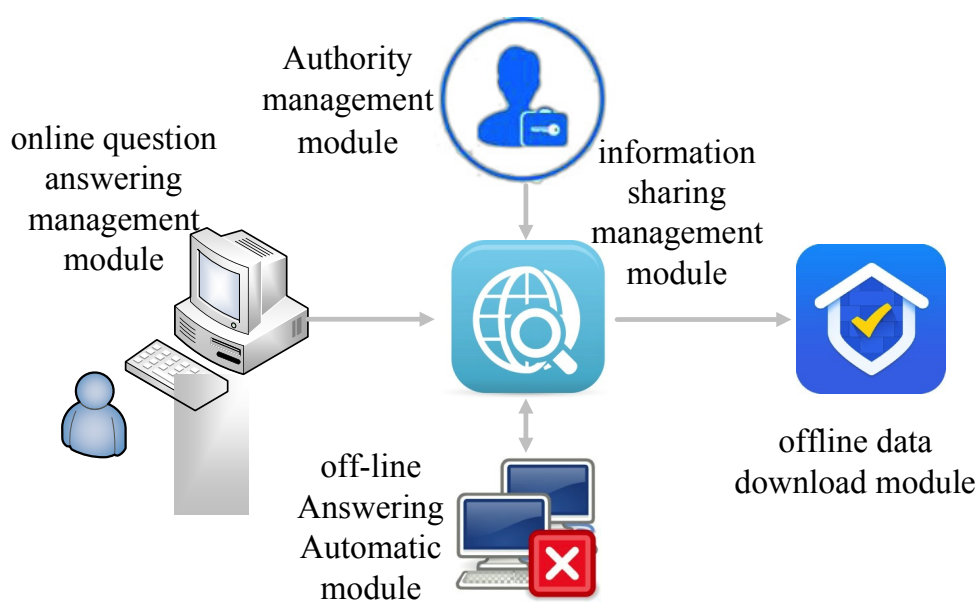

Fig. 4. Specific structure of distance backstage management center

Online question answering module conducts online question answering in audio/video form after online connection of user question signal accessed to remote terminal through network. Information sharing management module can store data package of the last module in real time to generate automatic answering module. Authority management module can achieve editing of data package stored. Offline automatic answering module can compare the similarity of user's questions through key characters and then complete automatic answering. Users can download data package through offline data download module. Flash-based distance question answering link for Gymnastics is shown in Fig.5:

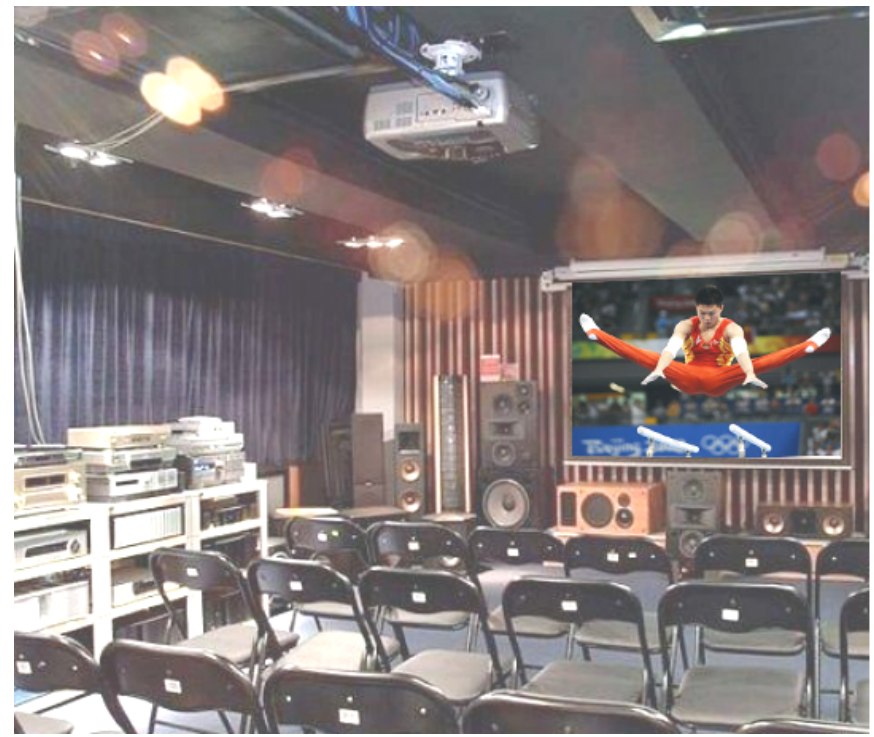

Fig. 5. Flash-based distance teaching display for Gymnastics 


\subsection{Effect check}

Based on the design of Flash-based multimedia teaching platform, Gymnastics was used as the experimental course to study the application effect of the teaching platform. Gymnastics is one of main courses in PE major. The course lasted for 1 year. The teaching objective was to make students grasp basic theory and basic knowledge of Gymnastics so as to give play to its function in exercise training practice and body building.

The college students of P.E. College in a university were chosen as the object of study. 96 students majoring in PE were chosen at random to participate in learning Gymnastics. Flash-based multimedia teaching platform was used to teach Gymnastics.

After the course ended, questionnaire survey was applied to gain students' evaluation of teaching effect. Teaching effect evaluation included 5 questions, and each questions involved 3 options: great help, some help, and no help. 96 questionnaires were distributed in total, and 96 effective questionnaires were recovered, with $100 \%$ effective recovery rate. Based on the questionnaire survey results, the statistics of students' teaching effect evaluation is as table 1 :

Table 1. Test paper setting

\begin{tabular}{|l|c|c|c|}
\hline \multicolumn{1}{|c|}{ Item } & Great help & Some help & No help \\
\hline $\begin{array}{l}\text { Enhance the cognition of importance of Gymnastics for } \\
\text { PE major }\end{array}$ & $88(91.7 \%)$ & $8(8.3 \%)$ & 0 \\
\hline Enhance learning interest & $86(89.6 \%)$ & $10(10.4 \%)$ & 0 \\
\hline Promote learning initiative and enthusiasm & $80(83.3 \%)$ & $16(16.7 \%)$ & 0 \\
\hline Better understand scientific exercise training principles & $80(83.3 \%)$ & $12(12.5 \%)$ & $4(4.17 \%)$ \\
\hline Increase knowledge expansion & $76(79.2 \%)$ & $14(14.6 \%)$ & $6(6.3 \%)$ \\
\hline
\end{tabular}

It is known from the table that, more than $90 \%$ of students considered that, Flashbased multimedia teaching platform make them realize the importance of Gymnastics for PE major. $89.6 \%$ of students thought that, the teaching platform is of great help for enhancing learning interest. Most students participating in questionnaire survey believed that Flash-based multimedia teaching platform could promote their learning initiative and enthusiasm and make them better understand scientific exercise training principles.

Generally speaking, Flash-based multimedia teaching platform can reach the expected development objective and has significant promotion effect for college PE teaching. Firstly, the teaching platform adopts the most excellent FLV streaming media coding technique, connects Flash Media Server2 service through FLASH platform, achieves "selective real-time teaching video playing function", "distance student-teacher video exchange function", "teaching discussion function" and "teacher tutoring function", solves non-smooth exchange between the teacher and students in distance teaching, effectively reduces the requirement of distance education information communication for network bandwidth, lowers teaching difficulty and teaching cost, and improves teaching quality and effect. Secondly, the teaching platform 
can offer a live classroom, i.e. virtual classroom. Fast communication of teaching resource can be achieved through video streaming service technology of Flash to make students learn anytime and anywhere through the rich multimedia courseware, which indirectly enhances students' mastery of gymnastic movement. Meanwhile, the application of video on demand provides a convenient channel for students' independent study, and contributes to enhancing students' learning interest and learning initiative.

\section{Conclusions}

Flash-based multimedia teaching platform has gained good feedbacks in practical teaching of Gymnastics and can effectively solve the problems of previous multimedia teaching platform such as poor interactivity, poor display effect and high cost. On the one hand, Flash-based teaching resource can meet vividness and individuation requirements of Gymnastics teaching, which has great significance for cultivating students' learning interest and expanding course content. Therefore, Flash-based multimedia teaching platform has a very extensive application prospect in college major teaching represented by PE courses, and owns great promotion value.

\section{References}

[1] Pattanaik, M. Design and Analysis of a Novel Low-Power SRAM Bit-Cell Structure at Deep-Sub-Micron CMOS Technology for Mobile Multimedia Applications. International Journal of Advanced Computer Science \& Application, 2011, vol. 2(2), pp. 43-49.

[2] Starren, J., Lai, A.M. Evaluation of a Remote Training Approach for Teaching Seniors to Use a Telehealth System. International Journal of Medical Informatics, 2009, vol. 78(11), pp. 732-744. https://doi.org/10.1016/j.ijmedinf.2009.06.005

[3] Lei, M., Ning, L., Xie, Y.G., et al. Development of a New Remote Experimental Teaching System. Research \& Exploration in Laboratory, 2009, vol. 28(4), pp. 229-231.

[4] Pan, J.B. Design and Realization on a Multimedia Instruction System Based on C/S. Journal of Hohai University Changzhou, 2001, vol. 15(2), pp. 28-31.

[5] Hui, Z. Design and Implement of Long-Distance Education System Base on Stream Media Technology. Advanced Materials Research, 2014, vol. 926-930, pp. 4477-4480. https://doi.org/10.4028/www.scientific.net/AMR.926-930.4477

[6] Zhou, Y., Tang, Y., Gong, Z., et al. Analysis on the Education of Traditional Chinese Medicine Culture in Higher Vocational Colleges of Traditional Chinese Medicine. Chinese Medicine Modern Distance Education of China, 2017, vol. 15(16), pp. 30-32.

[7] Xu, D., Zhong, S.C., Ma, X.C. Design and Implementation of Elementary School Solid Geomery Teaching Platform Based on the Flash3D Technology. Modern Educational Technology, 2013, vol. 23(4), pp. 119-124.

[8] Guo, X., Xi, Y. The design and implementation of a network teaching platform for Modern Electronic Technology Experiments. Experimental Technology \& Management, 2010, vol. 27(2), pp. 100-103.

[9] Ubul, K. Flash-Based Platform for Teaching Stored Program-Controlled Switching Courses. International Journal of Emerging Technologies in Learning, 2014, vol. 9(4), pp. 14-19. https://doi.org/10.3991/ijet.v9i4.3462 
[10] Kuriyan, R., Griffiths J K, Finkelstein J L, et al. Innovations in nutrition education and global health: the Bangalore Boston nutrition collaborative. Bmc Medical Education, 2014, vol. 14(1), pp. 1-10. https://doi.org/10.1186/1472-6920-14-5

\section{Author}

Changhui Xia is a Lecturer of PE College, Hubei University of Arts and Science, Xiangyang, 441053, China. His research interests include physical education and Multimedia Teaching. (shangwei12@yeah.net).

Article submitted 07 February 2018. Resubmitted 15 March 2018. Final acceptance 28 March 2018. Final version published as submitted by the authors. 